\title{
TO STUDY THE EFFECT OF LAPAROSCOPIC BARIATRIC SURGERY ON SERUM INSULIN LEVELS IN MORBIDLY OBESE PATIENTS
}

\author{
Tejinderpal Singh ${ }^{1}$, Ashish Ahuja², Anju Bhagtana ${ }^{3}$ \\ 1 Junior Resident, Department of Surgery, DMC Hospital, Ludhiana. \\ ${ }^{2}$ Associate Professor, Department of Surgery, DMC Hospital. Ludhiana. \\ ${ }^{3}$ Senior Resident, Department of Surgery, DMC Hospital. Ludhiana.
}

\section{ABSTRACT}

\section{BACKGROUND}

Obesity has emerged as one of the most serious public health concerns in the $21^{\text {st }}$ century. Obesity is a very important factor in the development of type 2 diabetes. The most commonly performed type of bariatric surgery, Roux-En-Y gastric bypass, improves diabetes not only through rapid weight-loss, but also by excluding (bypassing) a portion of the small intestine from the flow of nutrients. This means that gastric bypass surgery improves diabetes even before weight is lost. The production of various gut hormones is changed following gastric bypass, leading to improvement of insulin secretion. Weight loss is associated with an improvement in fasting glucose, insulin resistance and impaired dyslipidaemia.

Aim of the study is to evaluate the effect on serum insulin levels following laparoscopic bariatric surgery in morbidly obese patients at 1 month and 3 months post-op.

\section{MATERIALS AND METHODS}

The study was conducted in the Department of Surgery, DMCH, Ludhiana, on morbidly obese patients aged $37.4 \pm 15$ years, who were admitted, during a period of 15 months, undertaken to monitor the metabolic responses of serum insulin level, and weight reduction, after laparoscopic bariatric procedure.

\section{RESULTS}

Out of 31, $20(64.5 \%)$ patients were female and rest 11 were male. Mean age of patients was $46.94 \pm 11.53$ years. Mean height and weight was $1.65 \pm 0.055 \mathrm{~m}$ and $126.13 \pm 24.19 \mathrm{~kg}$ respectively. Mean BMI was $46.31 \pm 8.50 \mathrm{~kg} / \mathrm{m} .^{2}$ Out of 31 patients, 19 were hypertensive, and 14 were diabetics, on regular medications. All the 31 patients in this study with the mean serum insulin levels of $73.08 \pm 27.80$ preoperatively show significant fall in serum insulin levels at 1 month and 3 months $(p=0.00)$ postoperatively.

\section{CONCLUSION}

Laparoscopic bariatric surgery has resulted in resolution or decrease in doses of insulin in people who have T2DM.

\section{KEYWORDS}

Obesity, Laparoscopic, Insulin, Diabetes, Bariatric.

HOW TO CITE THIS ARTICLE: Singh T, Ahuja A, Bhagtana A. To study the effect of laparoscopic bariatric surgery on serum insulin levels in morbidly obese patients. J. Evolution Med. Dent. Sci. 2017;6(29):2396-2399, DOI: 10.14260/Jemds/2017/516

\section{BACKGROUND \\ Obesity has emerged as one of the most serious public health concerns in the $21^{\text {st }}$ century. It is a leading preventable cause of death worldwide, with increasing rates in adults and children and is seen as one of the most serious public health problems of the 21st century.[1] An obese person has double the risk of developing diabetes, and a severely obese person is at a tenfold increased risk.[2] Recent studies show that fat tissues change following bariatric surgery, which leads to improvement of insulin resistance. Gastric bypass surgery improves diabetes even before weight is lost.}

Financial or Other, Competing Interest: None.

Submission 05-01-2017, Peer Review 04-02-2017,

Acceptance 10-02-2017, Published 10-04-2017.

Corresponding Author:

Dr. Ashish Ahuja,

\#132/1, Rani Jhansi Road,

Civil Lines,

Ludhiana,

Punjab.

E-mail:drahuja17@gmail.com

DOI: $10.14260 /$ jemds $/ 2017 / 516$
The production of various gut hormones is changed following gastric bypass, leading to improvement of insulin secretion. Insulin resistance is defined as the diminished ability of muscle and other insulin-responsive tissue to transport glucose from the bloodstream into the cell. [3] The consequences of obesity and insulin resistance include high glucose and free fatty acid levels, elevated insulin and leptin concentrations and low adiponectin levels; other metabolic markers include high C-reactive protein (CRP) and tumour necrosis factor (TNF) alpha levels. ${ }^{[4]}$

Surgical intervention in obesity is today the most effective treatment method in high level obesity management with long-term clinical results and satisfaction of operated patients.[5] A high percentage of patients benefit from bariatric surgery procedures in terms of metabolic effect and substantial body mass index reduction. These procedures improve glucose metabolism leading to the amelioration or complete resolution of type 2 diabetes, reduction of insulin resistance and alleviation of metabolic syndrome effects. Bariatric surgery interventions not only ensure body weight reduction, but may influence lipid and saccharide metabolism as well. 
Weight loss is associated with an improvement in fasting glucose, insulin resistance and impaired dyslipidaemia.[6] Thus, it appears very important to evaluate rapid and significant reductions of weight after bariatric surgery techniques, on biochemical and anthropometric profiles in morbidly obese patients. Management of dyslipidaemia and insulin resistance is critically important in the prevention of many of these disorders including coronary artery disease in these patients.[7] Increased serum levels of low density lipoprotein cholesterol (LDL-C) and/or serum triglycerides (TG) and decreased high-density lipoprotein cholesterol levels (HDL-C) are atherogenic and have frequently been reported in this population. Many studies have shown reduction in hepatic transaminase and Gamma-GT levels post-bariatric surgery. $20-30 \%$ of obese patients without concomitant liver disease show elevated liver tests (ALT, AST, and GGT) which are known to normalise after weight reduction. ${ }^{[8]}$

\section{MATERIALS AND METHODS}

The study was conducted in the Department of Surgery, DMCH, Ludhiana, on morbidly obese patients aged $37.4 \pm 15$ years, who were admitted, during a period of 15 months, undertaken to monitor the metabolic responses of serum insulin level, and weight reduction, after laparoscopic bariatric procedure. This report presents the results of examined patients in 3 months after the operation. Interpretation was done on the basis of changes in Body Mass Index, Serum Insulin Levels, Lipid Profile and SGOT/SGPT in these patients.

Particulars of each patient were duly noted including name, age, sex, occupation, admission number, occupation and address for future correspondence. A written informed consent was taken from all the patients. Surgery will be performed according to patient's choice/subject to fitness.

Detailed history of each patient was obtained including history of presenting symptoms, any pre-existing comorbid conditions and the patient's past history including treatment and surgical history.

General physical examination and thorough systemic examination was done upon all patients at the time of admission. All necessary routine investigations were done. Pre-operatively and post-operatively at 1 month and 3 months, all patients underwent specific anthropometric measurements and laboratory investigations, as depicted in Table 1.

\begin{tabular}{|c|c|c|c|}
\hline \multirow{2}{*}{ Parameters } & \multirow{2}{*}{ Pre-Operative } & \multicolumn{2}{|c|}{ Post-Operative } \\
\cline { 3 - 4 } & & 1 month & 3 months \\
\hline Weight $(\mathrm{kg})$ & 126.13 & 116.13 & 97.26 \\
\hline BMI $\left(\mathrm{kg} / \mathrm{m}^{2}\right)$ & 46.31 & 42.68 & 35.69 \\
\hline Serum insulin levels & 73.08 & 67.73 & 56.53 \\
\hline SGOT & 30.61 & 30.61 & 29.87 \\
\hline SGPT & 29.39 & 29.45 & 27.97 \\
\hline Lipid Profile & & & \\
\hline Serum triglycerides & 169.16 & 159.39 & 150.48 \\
\hline Serum cholesterol & 145.23 & 136.61 & 129.84 \\
\hline HDL & 37 & 42.32 & 46.42 \\
\hline LDL & 102.42 & 95.94 & 89.97 \\
\hline \multicolumn{4}{|c}{} \\
\hline
\end{tabular}

The outcome of the study was assessed by monitoring the metabolic responses of serum insulin level and weight reduction after laparoscopic bariatric procedure. Appropriate statistical methods and tests were applied.

\section{RESULTS}

Out of $31,20(64.5 \%)$ patients were female and rest 11 were male. Mean age of patients was $46.94 \pm 11.53$ years. Mean height and weight was $1.65 \pm 0.055 \mathrm{~m}$ and $126.13 \pm 24.19 \mathrm{~kg}$ respectively. Mean BMI was $46.31 \pm 8.50 \mathrm{~kg} / \mathrm{m} .^{2}$ Out of 31 patients, 19 were hypertensive, and 14 were diabetics, on regular medications as shown in tables.

\begin{tabular}{|c|c|}
\hline Number (n) & 31 \\
\hline Mean Age (years) & $46.94 \pm 11.53$ \\
\hline Mean Height $(\mathrm{cm})$ & $165 \pm 5.5$ \\
\hline Mean Weight $(\mathrm{Kg})$ & $126.13 \pm 24.19$ \\
\hline Mean BMI $\left(\mathrm{kg} / \mathrm{m}^{2}\right)$ & $46.31 \pm 8.50$ \\
\hline \multicolumn{2}{|c|}{ Table 2 } \\
\hline
\end{tabular}

\section{Effect on Serum Insulin Levels}

All the 31 patients in this study with the mean Serum Insulin Levels of $73.08 \pm 27.80$ preoperatively show significant fall in Serum Insulin Levels at 1 month and 3 months $(p=0.00)$ postoperatively as shown in Table 5 and Figure 10. This signifies that Laparoscopic Bariatric surgery resulted in resolution of insulin resistance following the procedure.

\begin{tabular}{|c|c|c|c|}
\hline Serum Insulin Levels & Mean & Std. Deviation & N \\
\hline Pre-op & 73.08 & 27.80 & 31 \\
\hline Post-op month-1 & 67.73 & 29.03 & 31 \\
\hline Post-op month-3 & 56.53 & 28.12 & 31 \\
\hline \multicolumn{2}{|r|}{ Table 3. Effect on Serum Insulin Levels } \\
\hline
\end{tabular}

\section{Mean Weight Loss}

Pre-operatively mean weight was $126.13 \pm 24.19 \mathrm{~kg}$. Significant weight loss was observed at 1 month and 3 months when mean weight was $116.13 \pm 22.99 \mathrm{~kg} \& 97.26 \pm$ $23.38 \mathrm{~kg}$ respectively. Thus, concluding that bariatric procedure results in effective weight loss.

\begin{tabular}{|c|c|c|c|}
\hline Weight (kg) & Mean & Std. Deviation & N \\
\hline Pre-op & 126.13 & 24.19 & 31 \\
\hline Post-op month-1 & 116.13 & 22.99 & 31 \\
\hline Post-op month-3 & 97.26 & 23.38 & 31 \\
\hline \multicolumn{3}{|c|}{ Table 4. Mean Weight Loss } \\
\hline
\end{tabular}

\section{Effect on Body Mass Index (BMI)}

BMI (Body mass index) is calculated by weight (in $\mathrm{kg}$ ) divided by height (in $\mathrm{m}^{2}$ ). This is the main parameter depending upon which patient becomes eligible for bariatric surgery. Preoperatively BMI was $46.31 \pm 8.50 \mathrm{~kg} / \mathrm{m}^{2}$. Significant reduction in BMI was observed at 1 month and 3 months when mean BMI was $42.68 \pm 8.11 \mathrm{~kg} / \mathrm{m}^{2} \& 35.69 \pm 8.18 \mathrm{~kg} / \mathrm{m}^{2}$ respectively. Table 9 and figure 12 shows marked decrease in BMI of the patients at 1 and 3 months postoperatively which was statistically highly significant.

\begin{tabular}{|c|c|c|c|}
\hline BMI (Kg/m & Mean & Std. Deviation & N \\
\hline Pre-op & 46.31 & 8.50 & 31 \\
\hline Post-op month-1 & 42.68 & 8.11 & 31 \\
\hline Post-op month-3 & 35.69 & 8.18 & 31 \\
\hline \multicolumn{2}{|r|}{ Table 5. Effect on Body Mass Index }
\end{tabular}




\section{Effect on Serum Cholesterol}

Serum cholesterol levels showed a significant improvement at the end of 1 month (mean: $136.61 \pm 40.20 \mathrm{mg} / \mathrm{dL}$ ) when compared with pre-operative levels (mean: 145.23 \pm 45.73 $\mathrm{mg} / \mathrm{dL})$ and highly significant $(\mathrm{p}=.00)$ at 3 months (mean: $129.84 \pm 31.91 \mathrm{mg} / \mathrm{dL}$ ).

\begin{tabular}{|c|c|c|c|}
\hline S. Cholesterol & Mean & Std. Deviation & N \\
\hline Pre-op & 145.23 & 45.73 & 31 \\
\hline Post-op month-1 & 136.61 & 40.20 & 31 \\
\hline Post-op month-3 & 129.84 & 31.91 & 31 \\
\hline \multicolumn{2}{|r|}{ Table 6. Effect on Serum Cholesterol } \\
\hline
\end{tabular}

\section{Effect on Serum Triglycerides Levels}

In our study, serum triglyceride levels showed improvement at the end of 1 month (mean: $159.39 \pm 67.08 \mathrm{mg} / \mathrm{dL}$ ) when compared with pre-operative levels (mean: $169.16 \pm 73.72$ $\mathrm{mg} / \mathrm{dL})$ and significant improvement $(\mathrm{p}=.000)$ at 3 months (mean: $150.48 \pm 54.50 \mathrm{mg} / \mathrm{dL}$ ).

\begin{tabular}{|c|c|c|c|}
\hline $\begin{array}{c}\text { Serum Triglycerides } \\
\text { Levels }\end{array}$ & Mean & $\begin{array}{c}\text { Std. } \\
\text { Deviation }\end{array}$ & N \\
\hline Pre-op & 169.16 & 73.72 & 31 \\
\hline Post-op month-1 & 159.39 & 67.08 & 31 \\
\hline Post-op month-3 & 150.48 & 54.50 & 31 \\
\hline \multicolumn{2}{|c|}{ Table 7. Effect on Serum Triglycerides Levels } \\
\hline
\end{tabular}

\section{DISCUSSION}

Success or failure of any weight reducing technique is measured by extent of reduction in body weight, which is an important parameter of this study. In our study, mean weight following Bariatric Surgery at 1 month and 3 months was $126.13 \pm 24.19$ and $97.26 \pm 23.38 \mathrm{~kg}$ respectively. Most of the patients had lost more than $50 \%$ of the excess weight in 3 months following surgery with mean $\%$ excess weight loss (\%EWL) at 1 month and 3 months being 19.13\% and 56.78\% respectively. There was a significant decrease in BMI at 3 months following Bariatric surgery in our study group with mean BMI at the end of 1 month and 3 months being 42.68 $\mathrm{kg} / \mathrm{m}^{2}$ and $35.69 \mathrm{~kg} / \mathrm{m}^{2}$ as compared to the pre-op values of $46.31 \mathrm{~kg} / \mathrm{m}^{2}$.

Similar results were found by Alagna et al.[9] at mean $12 \pm 1$ months after surgery, the patients showed a significant decrease in weight, from $132.1 \pm 36.9$ before surgery to $93.5 \pm 20 \mathrm{~kg}(\mathrm{P}<.0001)$, and $\mathrm{BMI}$, from $47.3 \pm 13.1$ before surgery to $33.5 \pm 7(\mathrm{P}<.0001)$.

Omana et al[10] found similar results when studied men undergoing surgery lost weight; the percentage of excess weight loss was $61.48 \%$ (confidence interval [CI], 47.387575.5725).

\section{Effect on Serum Insulin Level}

There is abundant evidence from many centres indicating that type 2 diabetes can be cured by gastric bypass and by other forms of bariatric surgery.[11-13] That this is achieved before appreciable loss of weight is an important clue to improving our understanding of insulin resistance. Whereas obesity is conventionally thought to produce insulin resistance, it may emerge that obesity is another manifestation of insulin resistance. Put simply, insulin resistance may cause obesity, not vice versa. It has been postulated that gastric bypass improves diabetes through influences on the entero-insular axis, through a humoral effect.[14-15]

In our study, there was significant reduction in levels of Serum Insulin Levels at 1 month and 3 months postoperatively in obese patients with mean Serum Insulin level at 1 month and 3 months being 67.73 and 56.53 respectively as compared to the mean pre-operative value of 73.08 .

The decrease in insulin resistance after bariatric procedures results from multiple changes that occur postoperatively such as dietary control, decreased plasma ghrelin levels, which in turn leads to increase in maximal capacity of glucose-induced insulin release by the islet cells.

\section{Effect of Serum Lipid Levels}

Dyslipidaemia is a recognised cardiovascular risk factor in obese patients. In our study, there was a significant decrease in S. Cholesterol and S. Triglycerides levels at 3 months with a significant improvement in S.HDL levels. S.LDL levels also showed a decreasing trend; however, not statistically significant in this study, citing further followup to 1-2 years. Similar results were found in a study conducted by Chowbey et al who showed resolution of dyslipidaemia in $34 \%$ of the patients with significant decrease in mean cholesterol and LDL levels 6 months after LSG.[16]

\section{CONCLUSION}

Laparoscopic bariatric surgery is a good weight loss technique for obese and super obese patients. It produces sustainable weight loss with lesser complications both intraoperatively and postoperatively with shorter hospital stay and improvement in insulin resistance. After Laparoscopic bariatric surgery, Serum Insulin Levels started returning to normal in majority of patients. This effect started occurring after 1 month of Laparoscopic bariatric surgery.

Laparoscopic bariatric surgery is effective in treating metabolic syndrome with resolution or improvement of glycaemic status in most cases 3 months after surgery. Laparoscopic bariatric surgery is highly effective for achieving weight loss in patients with morbid obesity. There was also significant improvement in their lipid profiles.

\section{REFERENCES}

[1] Chaturvedi A, Jane N. Obesity and insulin resistance: an overview. J Biol Sci Opinion 2014:2(6):369-72.

[2] Rogula T, Brethauer S, Chand B, et al. Bariatric surgery as a treatment for type 2 diabetes. Obesity Action Coalition. http://www.obesityaction.org/ educationalresources/resource-articles-2/weight-losssurgery/bariatric-surgery-as-a-treatment-for-type-2diabetes 2016.

[3] Insulin resistance definition. $2012 \mathrm{http}: / /$ www.medicinenet.com/insulin_resistance/article.htm

[4] Vázquez LA, Pazos F, Berrazueta JR, et al. Effects of changes in body weight and insulin resistance on inflammation and endothelial function in morbid obesity after bariatric surgery. J Clin Endocrinol Metab 2005;90(1):316-22. 
[5] Bužga M, Holeczy P, Svagera Z, et al. Effects of sleeve gastrectomy on parameters of lipid and glucose metabolism in obese women - 6 months after operation. Wideochir Inne Tech Maloinwazyjne 2013;8(1):22-8.

[6] Dixon JB, O'Brien PE. Lipid profile in the severely obese: changes with weight loss after lap-band surgery. Obes Res 2002;10(9):903-10.

[7] Golpaie A, Hosseinzadeh-Attar MJ, Hoseini M, et al. Changes in lipid profile and insulin resistance in morbidly obese patients following laparoscopic total gastric vertical plication. J Minim Invasive Surg Sci 2012;1(1):24-9.

[8] Albert S, Borovicka J, Thurnheer M, et al. Pre- and postoperative transaminase changes within the scope of gastric banding in morbid obesity. Praxis (Bern 1994) 2001;90(35):1459-64

[9] Alagna S, Cossu ML, Gallo P, et al. Biliopancreatic diversion: long-term effects on gonadal function in severely obese men. Surg Obes Relat Dis 2006;2(2):82-6.

[10] Omana JJ, Tamler R, Strohmayer E, et al. Sex hormones in men undergoing bariatric surgery. J Am Coll Surg 2009;209(3):S22-S23.
[11] Scheen AJ, Luyckx FH, Lefebvre PJ. The place of bariatric surgery in the management of the obese type 2 diabetic patient. Int Diab Monitor 1998;10:1-7.

[12] Dhabuwala A, Cannan RJ, Stubbs RS. Improvement in co-morbidities following weight loss from gastric bypass surgery. Obes Surg 2000;10(5):428-35.

[13] O'Brien PE, Dixon JB, Brown W, et al. The laparoscopic adjustable gastric band (Lap-Band): a prospective study of medium-term effects on weight, health and quality of life. Obes Surg 2002;12(5):652-60.

[14] Adami GF, Cordera R, Camerini G, et al. Recovery of insulin sensitivity in obese patients at short term after biliopancreatic diversion. J Surg Res 2003;113(2):21721.

[15] Pories WJ. Why does the gastric bypass control type 2 diabetes mellitus? Obes Surg 1992;2(4):303-13.

[16] Chowbey PK, Dhawan K, Khullar R. Laparoscopic sleeve gastrectomy: an Indian experience-surgical technique and early result. Obes Surg 2010;20(10):1340-7. 